\title{
VIM-D Regimen
}

National Cancer Institute

\section{Source}

National Cancer Institute. VIM-D Regimen. NCI Thesaurus. Code C64792.

A regimen consisting of etoposide, ifosfamide, mitoxantrone and dexamethasone used for treatment of relapsed or refractory Hodgkin Lymphoma. 